\section{A dynamic balance between gene activation and repression regulates the shade avoidance response in Arabidopsis}

\author{
Giovanna Sessa, ${ }^{1}$ Monica Carabelli, ${ }^{1}$ \\ Massimiliano Sassi, ${ }^{1}$ Andrea Ciolfi, ${ }^{1,2}$ Marco \\ Possenti, ${ }^{2}$ Francesca Mittempergher, ${ }^{1}$ \\ Jorg Becker, ${ }^{3}$ Giorgio Morelli, ${ }^{2}$ and Ida Ruberti ${ }^{1,4}$ \\ ${ }^{1}$ Institute of Molecular Biology and Pathology, National \\ Research Council, 00185 Rome, Italy; ${ }^{2}$ National Research \\ Institute for Food and Nutrition, 00178 Rome, Italy; \\ ${ }^{3}$ Affymetrix Core Facility, Instituto Gulbenkian de Ciencia, \\ 2780-156 Oeiras, Portugal
}

Plants grown under dense canopies perceive through the phytochrome system a reduction in the ratio of red to far-red light as a warning of competition, and this triggers a series of morphological changes to avoid shade. Several phytochrome signaling intermediates acting as positive regulators of accelerated elongation growth and induction of flowering in shade avoidance have been identified. Here we report that a negative regulatory mechanism ensures that in the presence of far-red-rich light an exaggerated plant response does not occur. Strikingly, this unpredicted negative regulatory mechanism is centrally involved in the attenuation of virtually all plant responses to canopy shade.

Supplemental material is available at http://www.genesdev.org.

Received August 25, 2005; revised version accepted September 29, 2005.

The shade avoidance response is a strategy of major adaptive significance to plants in natural communities. It is highly widespread in the angiosperms, and depends on the ability of the plant to perceive the presence of neighbors. Within a vegetation, the ratio of red to far-red (R/FR) is lowered by the absorption of red light by photosynthetic pigments. This light quality change is perceived through the phytochrome system as an unambiguous signal of the proximity of neighbors (Franklin et al. 2003; Chen et al. 2004). Upon sensing a low R/FR ratio, a shade-avoiding plant reacts very rapidly and enhances elongation growth at the expense of leaf development even before it is directly shaded. If the plant succeeds in the attempt to overgrow its neighbors and the photosynthetic organs perceive daylight again, the shade avoidance response is rapidly reverted through phytochrome photoconversion (Ballaré 1999; Smith 2000; Morelli and Ruberti 2002). Consistent with the rapidity of

[Keywords: Neighbor detection; phytochrome signaling; HFR1/SICS1 transcription factor]

${ }^{4}$ Corresponding author.

E-MAIL ida.ruberti@uniroma1.it; FAX 39-06-4991-2500.

Article and publication are at http://www.genesdev.org/cgi/doi/10.1101/ gad.364005. the elongation growth response to low R/FR and its reversibility upon perception of high $\mathrm{R} / \mathrm{FR}$, changes in gene expression are very rapid and reversible (Carabelli et al. 1996; Salter et al. 2003). The transcript level of the homeodomain-leucine zipper ATHB2 and basic helixloop-helix (bHLH) PIL1 transcription factor genes, functionally implicated in the elongation response provoked by neighbor detection (Steindler et al. 1999; Salter et al. 2003), increases within a few minutes of low R/FR exposure (Carabelli et al. 1996; Salter et al. 2003). Significantly, ATHB2 and PIL1 transcript levels fall very rapidly after transfer from low R/FR to high R/FR (Carabelli et al. 1996; Salter et al. 2003).

Here, we report that the same low R/FR signal that induces the expression of the positive regulators ATHB2 and PIL1 also triggers a rapid induction of a negative master regulatory gene, HFR1/SICS1. This factor acting as a negative controller of the shade avoidance response ensures that an exaggerated reaction does not occur when the plant is unsuccessful in escaping canopy shade.

\section{Results and Discussion}

We found that persistency of a low R/FR signal causes a decrease in ATHB2 transcript level (Supplementary Fig. S1) suggesting the existence of a negative regulatory mechanism operating in low $\mathrm{R} / \mathrm{FR}$ light to reduce the strength of the elongation response. To identify negative regulators of the shade avoidance response, we devised a two-step screen consisting of (1) the identification of regulatory genes rapidly induced by FR-rich light and still up-regulated after prolonged exposure to low R/FR, and (2) the selection of the corresponding mutants with an altered shade avoidance response but a normal phenotype in high R/FR.

Affymetrix Arabidopsis Genome GeneChip array (ATH1) analyses on young seedlings exposed to low $\mathrm{R} / \mathrm{FR}$ for $1 \mathrm{~h}$ and $4 \mathrm{~d}$ identified seven regulatory genes (Supplementary Table S1). The greatest increase in transcript level in response to both brief and prolonged exposure to low R/FR was observed for HFR1, a gene encoding a bHLH protein, previously identified as a component of phytochrome A (Fairchild et al. 2000; Fankhauser and Chory 2000; Soh et al. 2000) and cryptochrome 1 (Duek and Fankhauser 2003) signaling pathways. The HFR1 transcript increased in abundance by 15- and 32-fold at $1 \mathrm{~h}$ and $4 \mathrm{~d}$, respectively (Supplementary Table S1). Recent work demonstrated that light, irrespective of its quality, enhances HFR1 protein stability (Duek et al. 2004; Jang et al. 2005; Yang et al. 2005a,b). Thus, it seems likely that the increase in HFR1 transcript provoked by prolonged low R/FR may result in a consequential increase in HFR1 protein level.

To determine whether HFR 1 is functionally involved in the regulation of shade avoidance responses, we isolated homozygous $h f_{r} 1$ T-DNA insertional lines (Salk_037727 and Salk_049497, which we designated $h f r 1-\overline{4}$ and $h f r 1-5$, respectively). Sequence analyses showed that the T-DNA is inserted in the third intron in hfr1-4 (754 nucleotides [nt] downstream of the ATG), causing deletion of the bHLH domain, and $267 \mathrm{nt}$ upstream of the ATG in $h f r 1-5$. Northern blot analysis showed a stable band of $\sim 1.5 \mathrm{~kb}$ for the $h f r 1-4$ allele and 
no detectable band for the hfr1-5 allele (data not shown), indicating that at least the latter is a null allele.

To analyze the phenotype of these lines, seedlings were grown for $3 \mathrm{~d}$ under light-dark cycles, and then either maintained in high R/FR or transferred to low R/FR. Hypocotyl length was measured after $4 \mathrm{~d}$ in these treatments. No phenotypic alteration was observed in $h f r 1$ seedlings grown in high R/FR (Supplementary Fig. S2). By contrast, $h f r 1-4$ and $h f r 1-5$ seedlings transferred to low R/FR displayed elongated hypocotyls relative to wild type in low R/FR, evidence of an exaggerated shade avoidance response (Supplementary Fig. S2). Based on the $h f_{r} 1$ phenotype in low R/FR, we propose to refer to this mutant as hfr1/sics1 (slender in canopy shade).

To investigate whether HFR1/SICS1 affects shade avoidance responses other than hypocotyl elongation, wild type, $h f r 1-4 / \operatorname{sics} 1-1$, and $h f r 1-5 /$ sics $1-2$ seedlings were grown for $4 \mathrm{~d}$ under high $\mathrm{R} / \mathrm{FR}$, and then transferred to low R/FR. Phenotypes were analyzed after 6 and $14 \mathrm{~d}$ in this treatment. Cotyledon and leaf area were significantly smaller in $h f r 1 /$ sics 1 mutants than in wild type (Fig. 1A,C; Table 1). The complexity of the leaf vascular system was reduced in $h f r 1 /$ sics 1 mutants relative to wild type both at the seedling stage and at the end of the vegetative growth (Fig. 1B,D). Moreover, petioles were extremely elongated in $h f r 1 /$ sics 1 mutants relative to wild type (Fig. 1C; Table 1). Finally, prolonged exposure to low R/FR resulted in early flowering in both $h f r 1 /$ sics 1 alleles (Fig. 1E; Table 1). These results establish HFR1/ SICS1 as a general regulator of the shade avoidance response.

To gain insights into the mechanism through which HFR1/SICS1 prevents an exaggerated shade avoidance response, we analyzed the expression of ATHB2 in $h f r 1 /$ sics1 seedlings exposed to low R/FR. In wild-type seedlings, ATHB2 transcript reached its maximum at $30 \mathrm{~min}$ and then slowly decreased (Fig. 2A). Remarkably, the kinetic of $A T H B 2$ induction by low $\mathrm{R} / \mathrm{FR}$ is not significantly affected in seedlings lacking functional HFR1/ SICS1 whereas the decrease of the ATHB2 mRNA provoked by prolonged exposure to low R/FR in wild-type seedlings is essentially abolished in $h f r 1 /$ sics 1 mutants (Fig. 2A). On the other hand, returning the seedlings to high R/FR after $1 \mathrm{~h}$ exposure to low R/FR resulted in a rapid decrease of the $A T H B 2$ mRNA both in wild type and $h f_{r} 1 / \operatorname{sics} 1$ mutants (Fig. 2B), indicating that HFR1/ SICS1 is not required for the down-regulation of ATHB2 by high $\mathrm{R} / \mathrm{FR}$. The HFR1/SICS1 gene is also rapidly down-regulated by high R/FR (Fig. 2B).

These data strongly suggest that HFR1/SICS1 may down-regulate key regulators of the shade avoidance response in low R/FR to prevent an exaggerated reaction to changes in R/FR. To test this hypothesis we carried out Affymetrix Arabidopsis Genome GeneChip array (ATH1) analyses on young $h f r 1-4 / \operatorname{sics} 1-1$ and $h f r 1-5$ / sics1-2 seedlings exposed to low R/FR for $1 \mathrm{~d}$. No significant difference was found in $h f r 1 /$ sics 1 mutants grown in high $\mathrm{R} / \mathrm{FR}$ relative to wild type. By contrast, 31 genes showed a differential regulation in $h f r 1-4 / \operatorname{sics} 1-1$ and hfr1-5/sics1-2 seedlings exposed to low R/FR relative to wild type (fold-change $\geq 1.75$ ) (Supplementary Table S2). Notably, all of the 31 genes are up-regulated in $h f r 1 /$ sics 1 mutants relative to wild type (Fig. 3A). A functional analysis of the 31 genes revealed that a significant number of the genes displaying differential regulation encode transcription factors. Among them are ATHB2; PIL2, a gene up-regulated by low R/FR in wild-type seedlings encoding a bHLH protein similar to PIL1 (Salter et al. 2003); BIM1, a gene encoding a bHLH transcription factor recently implicated in brassinosteroid signaling (Yin et al. 2005); and several other genes encoding bHLH proteins (Supplementary Table S2; Bailey et al. 2003), one of
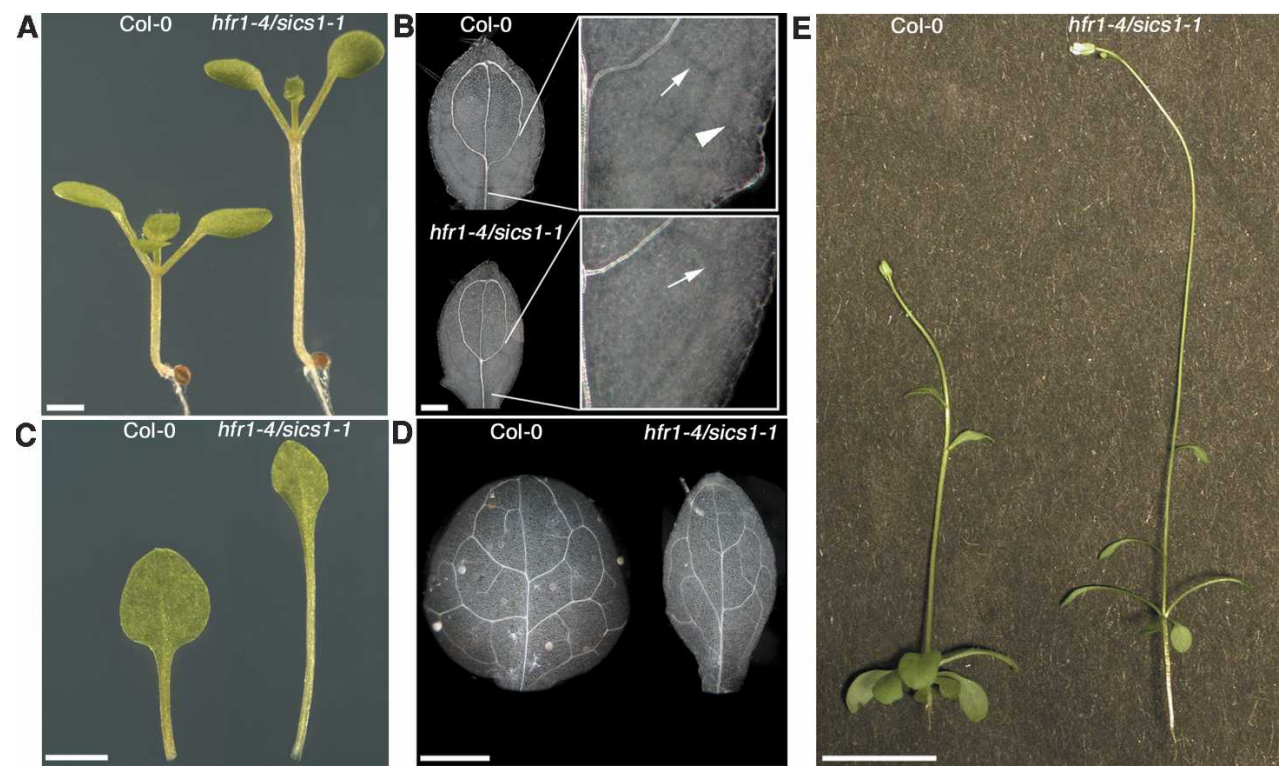

Figure 1. Exaggerated shade avoidance responses in hfr1/sics1 plants. (A) Col-0 and hfr1-4/sics1-1 seedlings grown for $4 \mathrm{~d}$ in high R/FR and subsequently for $6 \mathrm{~d}$ in low R/FR. $(B)$ Dark-field image of leaves from seedlings grown as in $A$ showing vascular strands. Insets show a magnification of the proximal right portion of the same leaves. At this stage, both wild-type and mutant leaves have formed the provascular loop of second order veins (arrows); the wild-type leaf has also formed the provascular strands of a third order vein (arrowhead). (C) Leaves of wild-type and $h f r 1-4 / s i c s 1-1$ plants grown for $4 \mathrm{~d}$ in high R/FR and subsequently for $14 \mathrm{~d}$ in low R/FR. (D) Dark-field image of leaves grown as in $C$ showing the vascular network. (E) Col-0 and hfr1-4/sics1-1 plants grown for $4 \mathrm{~d}$ in high R/FR and subsequently for $21 \mathrm{~d}$ in low R/FR. Bars: $A, D, 1 \mathrm{~mm} ; B, 100 \mu \mathrm{m} ; C, 2 \mathrm{~mm} ; E, 1 \mathrm{~cm}$. 
Table 1. Phenotypes of hfr1/sics1 plants grown in low $R / F R$

\begin{tabular}{lcccccc}
\hline Line & $\begin{array}{c}\text { Hypocotyl length } \\
(\mathrm{mm} \pm \mathrm{SEM})\end{array}$ & $\begin{array}{c}\text { Cotyledon petiole length } \\
(\mathrm{mm} \pm \mathrm{SEM})\end{array}$ & $\begin{array}{c}\text { Cotyledon area } \\
\left(\mathrm{mm}^{2} \pm \mathrm{SEM}\right)\end{array}$ & $\begin{array}{c}\text { Leaf petiole length } \\
(\mathrm{mm} \pm \mathrm{SEM})\end{array}$ & $\begin{array}{c}\text { Leaf area } \\
\left(\mathrm{mm}^{2} \pm \mathrm{SEM}\right)\end{array}$ & $\begin{array}{c}\text { No. of leaves } \\
(N \pm \mathrm{SEM})\end{array}$ \\
\hline Col-0 & $3.31 \pm 0.07$ & $1.94 \pm 0.05$ & $4.24 \pm 0.13$ & $3.39 \pm 0.08$ & $6.50 \pm 0.32$ & $3.68 \pm 0.10$ \\
hfr1-4/sics1-1 & $8.78 \pm 0.13^{\mathrm{a}}$ & $2.38 \pm 0.06^{\mathrm{a}}$ & $2.53 \pm 0.07^{\mathrm{a}}$ & $7.00 \pm 0.19^{\mathrm{a}}$ & $3.29 \pm 0.18^{\mathrm{a}}$ & $2.13 \pm 0.06^{\mathrm{a}}$ \\
hfr1-5/sics1-2 & $8.92 \pm 0.14^{\mathrm{a}}$ & $2.66 \pm 0.06^{\mathrm{a}}$ & $2.73 \pm 0.08^{\mathrm{a}}$ & $7.34 \pm 0.18^{\mathrm{a}}$ & $3.25 \pm 0.11^{\mathrm{a}}$ & $2.00 \pm 0.00^{\mathrm{a}}$ \\
\hline
\end{tabular}

Col-0, hfr1-4/sics1-1 and hfr1-5/sics1-2 plants were grown for $4 \mathrm{~d}$ in high R/FR and subsequently for $14 \mathrm{~d}$ in low R/FR.

At least 30 plants for each line were analyzed.

(SEM) Standard error of the mean.

${ }^{a} P<0.01$ (hfr1-4/sics1-1 or hfr1-5/sics1-2 vs. Col-0).

which was rapidly up-regulated by shade in wild-type seedlings (Devlin et al. 2003). Interestingly, the gene encoding PHYA, rapidly up-regulated by low R/FR in wildtype seedlings (Devlin et al. 2003), and PAT3-like/FHL encoding a protein similar to FHY1/PAT3, a positive regulator of PHYA signal transduction (Desnos et al. 2001; Zeidler et al. 2001, 2004), are also differentially regulated in $h f_{r} 1 /$ sics 1 seedlings exposed to low R/FR relative to wild type. Together, the data indicate that several regulatory genes, some of which already implicated in shade avoidance responses, are differentially regulated by low R/FR in wild type and $h f r 1 /$ sics 1 mutants. Among the 31 genes, one further group encodes hormone-related factors (Supplementary Table S2). Significantly, several genes implicated in auxin and gibberellin pathways are up-regulated in $h f_{r} 1 /$ sics 1 seedlings. AtCKX5, a gene encoding a cytokinin oxidase/ dehydrogenase involved in cytokinin breakdown (Werner et al. 2003), is also differentially regulated in hfr1/sics1 mutants. Links between the shade avoidance response and the auxin and gibberellin pathways have been established (Morelli and Ruberti 2002; Devlin et al. 2003; Vandenbussche and Van Der Straeten 2004). Therefore, the up-regulation of the auxin and gibberellin signaling pathways and the down-regulation of the cytokinin pathway in $h f r 1 /$ sics 1 seedlings in low R/FR relative to wild type is consistent with the enhanced shade avoidance response of these mutants.

We next examined the kinetic of induction by low $\mathrm{R} / \mathrm{FR}$ of seven genes selected among the 31 genes and PIL1, absent in the Affymetrix Arabidopsis Genome GeneChip array (ATH1), in wild-type and $h f r 1 /$ sics 1 seedlings. The lack of functional HFR1/SICS1 does not significantly affect the kinetic of induction of these genes by low R/FR (Fig. 3B). By contrast, the transcript level of all of the eight genes was significantly higher in $h f_{r} 1 /$ sics 1 seedlings than in wild type after prolonged exposure to low R/FR (Fig. 3B).

$F T$, encoding a key integrator of different floral induction signals including low R/FR (Cerdan and Chory 2003; Casal et al. 2004), was not identified as a gene significantly up-regulated in $h f r 1 /$ sics 1 mutants (Supplementary Table S2). However, consistent with the early-flowering phenotype of the mutants in low R/FR, quantitative PCR analysis showed that FT expression is substantially higher in $h f r 1 /$ sics 1 seedlings relative to wild type (Fig. 3C).

The results described here uncover a gas-and-brake mechanism for the control of the shade avoidance response acting through a dynamic balance of positive and negative transcriptional regulators. Positive regulators of the shade avoidance response are induced within a few minutes of a change in R/FR /Carabelli et al. 1996; Salter et al. 2003). These rapid changes in gene expression ensure a fast reshaping of the plant body toward a light environment optimal for growth. Low R/FR also provokes a rapid induction of the HFR1/SICS1 gene to negatively regulate the downstream signaling initiated by the same signal. HFR1/SICS1 acting as a negative controller of the shade avoidance response ensures that an exaggerated reaction does not occur when the plant is unsuccessful in escaping canopy shade. In this unfavorable environmental light condition, HFR1/SICS1 is likely to play a fundamental role in the acclimation of the plant both morphologically and biochemically, and by delaying flowering, to ensure a better seed production needed for long term survival.

HFR1/SICS1, already implicated in phytochrome A and cryptochrome 1 signaling during the de-etiolation process (Fairchild et al. 2000; Fankhauser and Chory 2000; Soh et al. 2000; Duek and Fankhauser 2003), might represent a point of convergence of photoreceptor signaling in canopy shade. While it is established that low $\mathrm{R} / \mathrm{FR}$ light is the primary cue for the detection of neighbors, and several phytochromes contribute to the perception of this signal (Franklin et al. 2003; Chen et al. 2004), recent findings indicated blue light and total light intensity as additional important cues within a vegetation (Vandenbussche et al. 2005). A major challenge in the future is to understand whether light signals perceived by different photoreceptors are integrated through

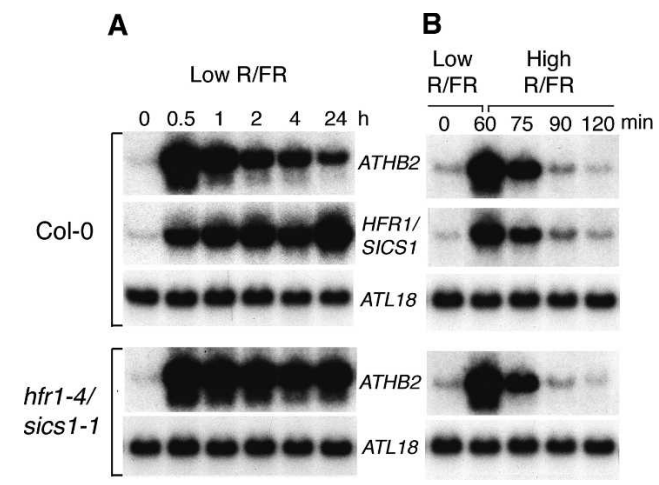

Figure 2. HFR1/SICS1 is required to down-regulate ATHB2 expression in low R/FR. (A) Northern analysis of ATHB2 in Col-0 and hfr1-4/sics1-1 seedlings grown in high R/FR (0) and then exposed to low R/FR for the indicated times. (B) Northern analysis of ATHB2 in Col-0 and hfr1-4/sics1-1 seedlings grown in high R/FR (0), and then exposed for $60 \mathrm{~min}$ to low R/FR (60), or exposed for $60 \mathrm{~min}$ to low R/FR and then returned to high R/FR for 15 min (75), 30 min (90), and $60 \mathrm{~min}(120)$. HFR1/SICS1 expression in Col-0 seedlings treated as described in $A$ and $B$ is also shown. ATL18 was used in $A$ and $B$ to monitor equal loading. 
Sessa et al.

A
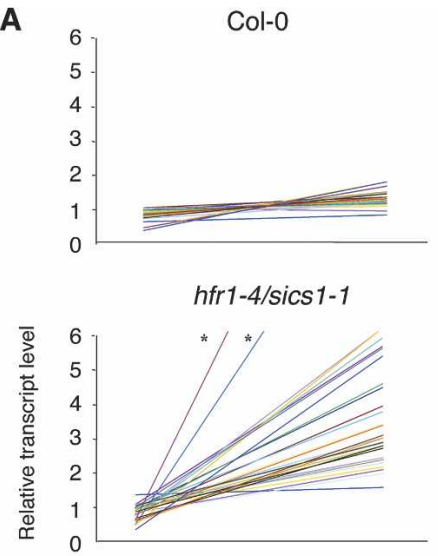

hfr $1-5 / \operatorname{sics} 1-2$

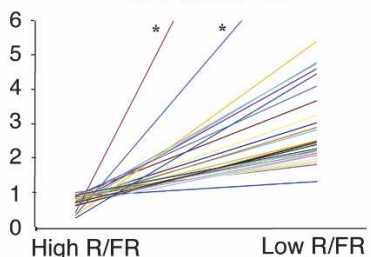

B

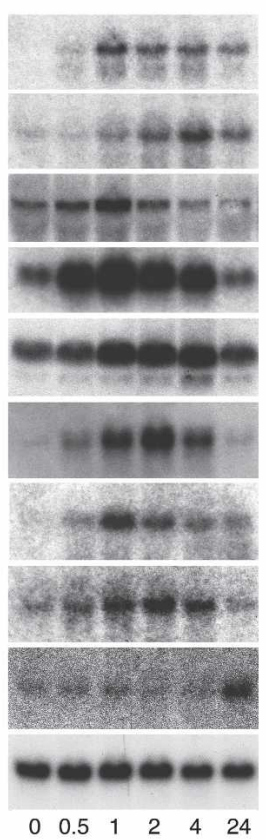

hfr1-4/sics $1-1$

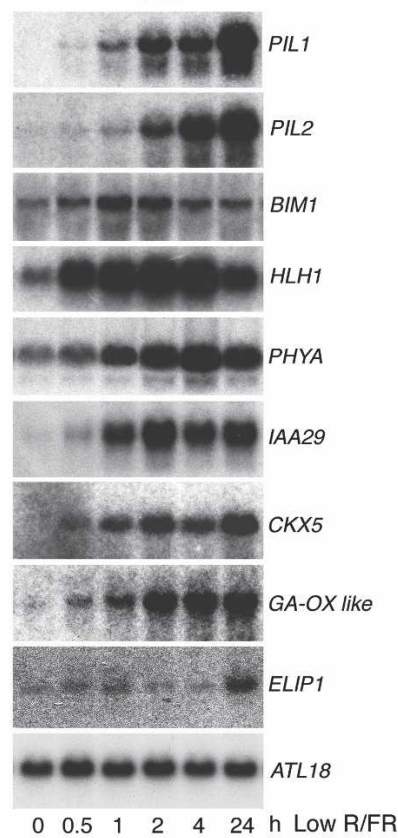

C

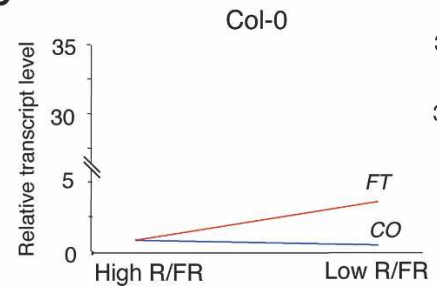

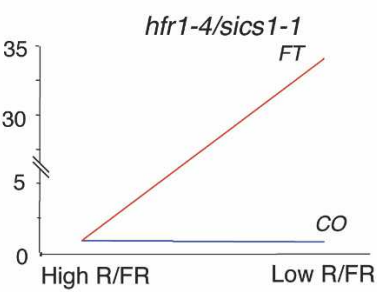

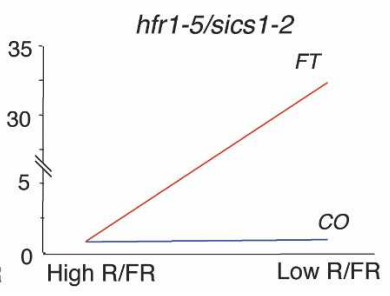

Figure 3. HFR1/SICS1 acts as a negative regulator in the signaling cascade induced by low R/FR. (A) Col-0, hfr1-4/sics1-1 and hfr1-5/sics1-2 seedlings were grown for $7 \mathrm{~d}$ in high R/FR and then either maintained in high R/FR or transferred to low R/FR for $1 \mathrm{~d}$. Global changes in gene expression were analyzed by means of Affymetrix Arabidopsis Genome GeneChip arrays (ATH1). The graphs show the relative expression levels in high and low R/FR of the genes differentially regulated in $h f r 1 /$ sics 1 seedlings relative to wild type after prolonged exposure to low R/FR (Supplementary Table S2). Asterisks indicate genes whose transcript levels in low R/FR are out of scale (maroon, AtSOT15; blue, IAA29). $(B)$ Northern analysis of PIL1, selected genes from A, and ELIP1, a gene not differentially regulated by low R/FR in $h$ fri/sics1 seedlings relative to wild type. Col-0 and hfr1-4/sics1-1 seedlings were grown in high R/FR (0) and then exposed to low R/FR for the indicated times. ATL18 was used to monitor equal loading. (C) Quantitative PCR analysis of CO (At5g15840) and FT in Col-0 and hfr1/sics1 seedlings grown as described in $A$. The graphs show the relative expression levels in high and low R/FR of $C O$ and $F T$ in the different genotypes. Each value is the mean of three separate quantitative PCR reactions normalized to actin2. Relative transcript abundance of $C O$ and $F T$ is normalized to their respective levels in Col-0 seedlings in high R/FR. The standard deviation for all values is $\leq 0.167$.

HFR1/SICS1 to prevent exaggerated responses under canopy shade.

\section{Materials and methods}

Plant growth conditions and phenotypic analyses

Wild-type strain used was Arabidopsis thaliana (L.) Heynh. var. Columbia (Col-0). hfr1-4/sics1-1 and $h$ fr1-5/sics1-2 seeds were obtained from NASC (SALK_037727 and SALK_049497, respectively). DNA sequences flanking the T-DNA insertions in $h f r 1-4 /$ sics1-1 and $h f r 1-5 /$ sics1-2 were amplified and sequenced, in order to precisely map the insertions. Homozygous lines were verified by PCR analyses. Plants were grown as previously described (Steindler et al. 1999) in a LED growth chamber (E30-LED, Percival Scientific Inc.), at $21^{\circ} \mathrm{C}$ temperature, $75 \%$ humidity, $16 \mathrm{~h}$ light/8 h dark cycles. Light outputs in high R/FR were $670 \mathrm{~nm}$ (Red), $96 \mu \mathrm{mol} \mathrm{m} \mathrm{m}^{-2} \mathrm{~s}^{-1} ; 735 \mathrm{~nm}$ (Far Red), $21 \mu \mathrm{mol} \mathrm{m} \mathrm{m}^{-2} \mathrm{~s}^{-1}$; and $470 \mathrm{~nm}$ (Blue), $15 \mu \mathrm{mol} \mathrm{m} \mathrm{m}^{-2}$. Light outputs in low R/FR were $670 \mathrm{~nm}, 12 \mu \mathrm{mol} \mathrm{m}{ }^{-2} \mathrm{~s}^{-1}$; $735 \mathrm{~nm}, 105 \mu \mathrm{mol} \mathrm{m}{ }^{-2} \mathrm{~s}^{-1}$; and $470 \mathrm{~nm}, 15 \mu \mathrm{mol} \mathrm{m}{ }^{-2} \mathrm{~s}^{-1}$. Images of whole seedlings and green leaves were taken under a MZ 12 binocular microscope (Leica), using a Spot Jr. digital camera (Diagnostic Instrument
Inc.), or pictured with a Coolpix 990 digital camera (Nikon Corp.). For hypocotyl, cotyledon, and leaf measurements, images were taken with the same devices, and subsequently analyzed with the Scion Image 1.63 software (Scion Corp.). Leaves were cleared according to the protocol previously described (Weigel and Glazebrook 2002). Cleared samples were analyzed under dark-field optics with an Axioskop 2 plus binocular microscope (Zeiss), and images taken with the Coolpix 990. T-test statistical analysis was performed using QuickCalcs Online Calculators for Scientists (GraphPad Software, Inc., http://graphpad.com/quickcalcs).

Gene expression analyses

For gene expression analyses, 8-d-old seedlings were harvested after the designated treatments for the indicated period of time. Total RNA was extracted using RNeasy Plant Mini Kit (Qiagen). Northern experiments were performed using $10 \mu \mathrm{g}$ of RNA as previously described (Carabelli et al. 1996). Details on the probes used are given in the Supplemental Material. For quantitative PCR experiments, total RNA was reverse-transcribed using the SuperScript III First-Strand Synthesis System (Invitrogen) according to the manufacturer's instructions. Quantitative PCR was performed with the SYBR Green PCR Master Mix (Applied Biosystems) using the ABI Prism 7900HT Sequence Detection Systems (Applied Bio- 
systems) according to the manufacturer's instructions. Each amplification was performed in triplicate using a primer concentration of $300 \mathrm{nM}$. Primer sequences are given in the Supplemental Material. Affymetrix Arabidopsis Genome GeneChip array (ATH1) experiments were performed at the Affymetrix Core Facility in the Instituto Gulbenkian de Ciencia. RNAs from two biological replicates were used to prepare hybridization probes according to the Affymetrix protocols. Hybridization and post-hybridization steps were as recommended by Affymetrix protocols. Scanned arrays were analyzed first with Affymetrix MAS 5.0 software to obtain Absent/Present calls and for subsequent analyses with DNA-Chip Analyzer (dChip) version 1.3 (http://www.dchip.org, Wong Lab, Harvard University). In dChip, arrays were normalized to the median overall intensity, chosen as a baseline (Li and Wong 2001a), and then expression values were calculated using PM-only model ( $\mathrm{Li}$ and Wong 2001b). Expression values were imported into GeneSpring 6.2.1 (Silicon Genetics) and scaled around 1 in two steps ("per chip" and "per gene" normalization). Subsequently, poor quality data were filtered out using the Cross-Gene Error Model (CGEM) (Rocke and Durbin 2001). A 1.75fold or greater change in expression between two samples was chosen as the cut-off for regulated versus not-regulated genes. On regulated genes, statistical analyses (one-way Welch ANOVA, variances calculated using CGEM) with multiple testing corrections (false discovery rate, $p$-value cut-off $=0.05$ ) were performed to find the genes varying significantly (Benjamini and Hochberg 1995). All data were submitted to ArrayExpress database (accession nos. E-MEXP-443 and E-MEXP-444) in compliance with MIAME checklist.

\section{Acknowledgments}

We thank the European Arabidopsis Stock Centre NASC for providing the SALK_037727 and SALK_049497 seeds. This work was supported, in part, by grants from Ministero dell'Istruzione, dell'Università e della Ricerca, Strategic Program Post-genomics FIRB and Ministero delle Politiche Agricole e Forestali, Agronanotech program.

\section{References}

Bailey, P.C., Martin, C., Toledo-Ortiz, G., Quail, P.H., Huq, E., Heim, M.A., Jakoby, M., Werber, M., and Weisshaar, B. 2003. Update on the basic helix-loop-helix transcription factor gene family in Arabidopsis thaliana. Plant Cell 15: 2497-2501.

Ballaré, C.L. 1999. Keeping up with neighbours: Phytochrome sensing and other signaling mechanisms. Trends Plant Sci. 4: 97-102.

Benjamini, Y. and Hochberg, Y. 1995. Controlling the false discovery rate: A practical and powerful approach to multiple testing. J. Roy. Statist. Soc. Ser. B 57: 289-300.

Carabelli, M. Morelli, G., Whitelam, G., and Ruberti, I. 1996. Twilightzone and canopy shade induction of the ATHB-2 homeobox gene in green plants. Proc. Nat1. Acad. Sci 93: 3530-3535.

Casal, J.J., Fankhauser, C., Coupland, G., and Blazquez, M.A. 2004. Signaling for developmental plasticity. Trends Plant Sci. 9: 309-314.

Cerdan, P.D. and Chory, J. 2003. Regulation of flowering time by light quality. Nature 423: 881-885.

Chen, M., Chory, J., and Fankhauser, C. 2004. Light signal transduction in higher plants. Annu. Rev. Genet. 38: 87-117.

Desnos, T., Puente, P., Whitelam, G.C., and Harberd, N.P. 2001. FHY1: A phytochrome A-specific signal transducer. Genes \& Dev. 15: 29802990.

Devlin, P.F., Yanovsky, M.J., and Kay, S.A. 2003. A genomic analysis of the shade avoidance response in Arabidopsis. Plant Physiol. 133: $1-13$.

Duek, P.D. and Fankhauser, C. 2003. HFR1, a putative bHLH transcription factor, mediates both phytochrome A and cryptochrome signaling. Plant T. 34: 827-836.

Duek, P.D., Elmer, M.V., van Oosten, V.R., and Fankhauser, C. 2004. The degradation of HFR1, a putative bHLH class transcription factor involved in light signaling, is regulated by phosphorylation and requires COP1. Curr. Biol. 14: 2296-2301.

Fairchild, C.D., Schumaker, M.A., and Quail, P.H. 2000. HFR1 encodes an atypical bHLH protein that acts in phytochrome A signal transduction. Genes \& Dev. 14: 2377-2391.

Fankhauser, C. and Chory, J. 2000. RSF1, an Arabidopsis locus implicated in phytochrome A signaling. Plant Physiol. 124: 39-45.
Franklin, K.A., Praekelt, U., Stoddart, W.M., Billingham, O.E., Halliday, K.J., and Whitelam, G.C. 2003. Phytochromes B, D and E act redundantly to control multiple physiological responses in Arabidopsis. Plant Physiol. 131: 1340-1346.

Jang, I.-C., Yang, J.-Y., Seo, H.S., and Chua, N.-H. 2005. HFR1 is targeted by COP1 E3 ligase for post-translational proteolysis during phytochrome A signaling. Genes \& Dev. 19: 593-602.

Li, C. and Wong, W.H. 2001a. Model-based analysis of oligonucleotide arrays: Expression index computation and outlier detection. Proc. Nat1. Acad. Sci. 98: 31-36.

- 2001b. Model-based analysis of oligonucleotide arrays: Model validation, design issues and standard error application. Genome Biol. 2: research0032.1-research0032.11.

Morelli, G. and Ruberti, I. 2002. Light and shade in the photocontrol of Arabidopsis growth. Trends Plant Sci. 7: 399-404.

Rocke, D.M. and Durbin, B. 2001. A model for measurement errors for gene expression arrays. J. Comput. Biol. 8: 557-569.

Salter, M.G., Franklin, K.A., and Whitelam, G.C. 2003. Gating of the rapid shade avoidance response by the circadian clock in plants. $\mathrm{Na}$ ture 426: 680-683.

Smith, H. 2000. Phytochromes and light signal perception by plants-An emerging synthesis. Nature 407: 585-591.

Soh, M.-S., Kim, Y.-M., Han, S.-J., and Song, P.-S. 2000. REP1, a basic helix-loop-helix protein, is required for a branch pathway of phytochrome A signaling in Arabidopsis. Plant Cell 12: 2061-2073.

Steindler, C., Matteucci, A., Sessa, G., Weimar, T., Ohgishi, M., Aoyama, T., Morelli, G., and Ruberti, I. 1999. Shade avoidance responses are mediated by the ATHB-2 HD-Zip protein, a negative regulator of gene expression. Development 125: 4235-4245.

Vandenbussche, F. and Van Der Straeten, D. 2004. Shaping the shoot: A circuitry that integrates multiple signals. Trends Plant Sci. 9: 499506.

Vandenbussche, F., Pierik, R., Millenaar, F.F., Voesenek, L.A.C.J., and Van Der Straeten, D. 2005. Reaching out of the shade. Curr. Opin. Plant Biol. 8: 1-7.

Weigel, D. and Glazebrook, J. 2002. Arabidopsis: A laboratory manual. Cold Spring Harbor Laboratory Press, Cold Spring Harbor, New York.

Werner, T., Motyka, V., Laucou, V., Smets, R., Van Onckelen, H., and Schmulling, T. 2003. Cytokinin-deficient transgenic Arabidopsis plants show multiple developmental alterations indicating opposite functions of cytokinins in the regulation of shoot and root meristem activity. Plant Cell 15: 2532-2550.

Yang, J., Lin, R., Sullivan, J., Hoecker, U., Liu, B., Xu, L., Deng, X. W., and Wang, H. 2005a. Light regulates COP1-mediated degradation of HFR1, a transcription factor essential for light signaling in Arabidopsis. Plant Cell 17: 804-821.

Yang, J., Lin, R., Hoecker, U., Liu, B., and Wang, H. 2005b. Repression of light signaling by Arabidopsis SPA1 involves post-translational regulation of HFR1 protein accumulation. Plant J. 43: 131-141.

Yin, Y., Vafeados, D., Tao, Y., Yoshida, S., Asami, T., and Chory, J. 2005. A new class of transcription factors mediates brassinosteroid-regulated gene expression in Arabidopsis. Cell 120: 249-259.

Zeidler, M., Bolle, C., and Chua, N.H. 2001. The phytochrome A specific signaling component PAT3 is a positive regulator of Arabidopsis photomorphogenesis. Plant Cell Physiol. 42: 1193-1200.

Zeidler, M., Zhou, Q., Sarda, X., Yau, C.-P., and Chua, N.-H. 2004. The nuclear localization signal and the C-terminal region of FHY1 are required for transmission of phytochrome A signal. Plant J. 40: 355365. 


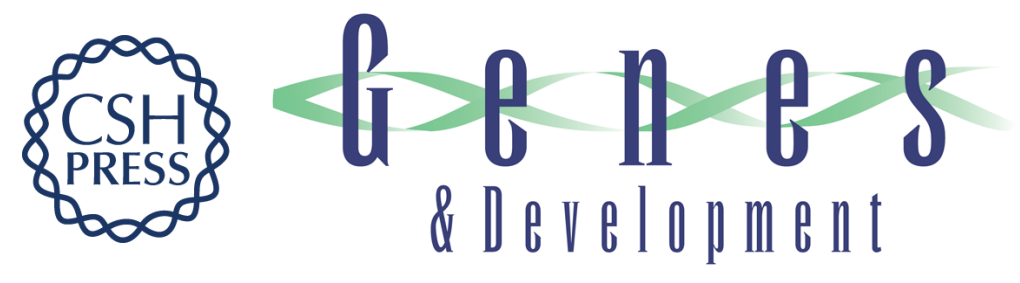

\section{A dynamic balance between gene activation and repression regulates the shade avoidance response in Arabidopsis}

Giovanna Sessa, Monica Carabelli, Massimiliano Sassi, et al.

Genes Dev. 2005, 19:

Access the most recent version at doi:10.1101/gad.364005

Supplemental
Material http://genesdev.cshlp.org/content/suppl/2005/12/02/19.23.2811.DC1

References This article cites 31 articles, 12 of which can be accessed free at:

http://genesdev.cshlp.org/content/19/23/2811.full.html\#ref-list-1

License

Email Alerting

Receive free email alerts when new articles cite this article - sign up in the box at the top

Service

right corner of the article or click here.

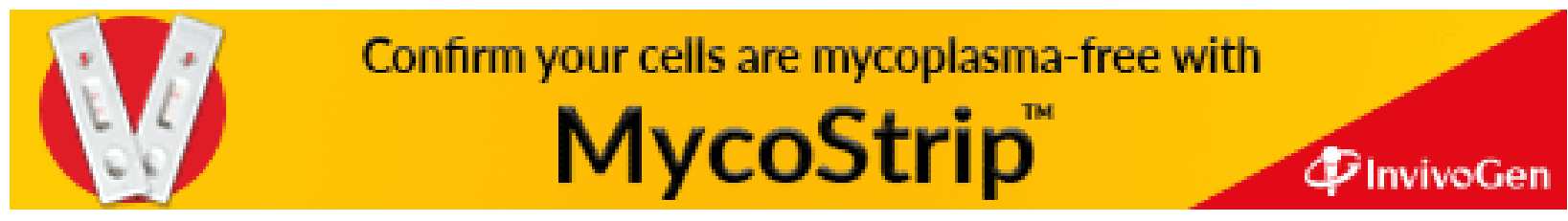

